\title{
Deficiency of $p 53$ accelerates mammary tumorigenesis in Wnt-1 transgenic mice and promotes chromosomal instability
}

\author{
Lawrence A. Donehower, ${ }^{1}$ Lucy A. Godley, ${ }^{2}$ C. Marcelo Aldaz, ${ }^{3}$ Ruth Pyle, ${ }^{1}$ Yu-Ping Shi, ${ }^{4}$ \\ Dan Pinkel, ${ }^{4}$ Joe Gray, ${ }^{4}$ Allan Bradley, ${ }^{5}$ Daniel Medina, ${ }^{6}$ and Harold E. Varmus ${ }^{2,7}$ \\ ${ }^{1}$ Division of Molecular Virology, Baylor College of Medicine, Houston, Texas 77030 USA; ${ }^{2}$ Varmus Laboratory, National \\ Cancer Institute, Bethesda, Maryland 20892 and Department of Biochemistry and Biophysics, University of California, San \\ Francisco, California 94143 USA; ${ }^{3}$ Department of Carcinogenesis, University of Texas M.D. Anderson Cancer \\ Center-Science Park, Smithville, Texas 78957 USA; ${ }^{4}$ Division of Molecular Cytometry, Department of Laboratory \\ Medicine, University of California at San Francisco, San Francisco, California 94143 USA; ${ }^{5}$ Institute for Molecular Genetics \\ and Howard Hughes Medical Institute, Baylor College of Medicine, Houston, Texas 77030 USA; ${ }^{6}$ Department of Cell \\ Biology, Baylor College of Medicine, Houston, Texas 77030 USA; $^{7}$ Office of the Director, National Institutes of Health, \\ Bethesda, Maryland 20892 and Department of Microbiology and Immunology, University of California, San Francisco, \\ California 94143 USA
}

By crossing mice that carry a null allele of $p 53$ with transgenic mice that develop mammary adenocarcinomas under the influence of a Wnt-1 transgene, we have studied the consequences of p53 deficiency in mammary gland neoplasia. In Wnt-1 transgenic mice homozygous for the p53 null allele, tumors appear at an earlier age than in animals heterozygous or wild-type at the p53 locus. About half of the tumors arising in p53 heterozygotes exhibit loss of the normal p53 allele, implying selection for p53-deficient cells. Mammary tumors lacking p53 display less fibrotic histopathology and increased genomic instability with aneuploidy, amplifications, and deletions, as detected by karyotype analysis and comparative genomic hybridization. In one tumor, the amplified region of chromosome 7 had an ectopically expressed int-2/FGF3 proto-oncogene, a gene known to cooperate with Wnt-1 in the production of mammary tumors. These findings favor a model in which p53 deficiency relaxes normal restraints on chromosomal number and organization during tumorigenesis.

[Key Words: p53; Wnt-1; mammary tumors; genomic instability; mouse; tumor model]

Received January 4, 1995; revised version accepted February 22, 1995.

The $p 53$ tumor suppressor gene is the known gene mutated most frequently in human cancers, with deletions and point mutations observed in almost half of all tumors and in about one-fourth of all sporadic breast cancers (Greenblatt et al. 1994). In addition to their frequent occurrence in spontaneously arising tumors, p53 mutations have also been identified in the germ line of some individuals with an inherited cancer predisposition called Li-Fraumeni syndrome (Malkin et al. 1990; Srivastava et al. 1990). The presence or absence of $p 53$ mutations in a human tumor may have important clinical implications. A number of studies have shown that tumors missing wild-type $p 53$ are likely to have a relatively poor prognosis (Callahan 1992; Thor et al. 1992). Moreover, tumors with mutant $p 53$ appear to be significantly more resistant to the effects of radiation and other anticancer drugs (Lowe et al. 1993a, 1994).

The importance of $p 53$ loss in cancer is illustrated further by genetically engineered mice that contain one or two defective germ-line $p 53$ alleles (Donehower et al. 1992; Jacks et al. 1994; Purdie et al. 1994). Mice with two defective $p 53$ alleles ( $p 53-/-$ ) are developmentally normal, but all succumb to tumors by the age of 10 months (Donehower et al. 1992; Harvey et al. 1993a,b; Jacks et al. 1994; Purdie et al. 1994). Mice with a single defective p53 allele $(p 53+/-)$ acquire tumors at a later age, but by 18 months half of these mice have developed cancer (Harvey et al. 1993a). Lymphomas and sarcomas are the most frequently observed tumor types in the p53-deficient animals, whereas carcinomas (including mammary adenocarcinomas) are only seen infrequently.

We have now developed an experimental model to study the role of p53 in mammary tumorigenesis by crossing mice that carry a disrupted p53 allele with transgenic mice programmed to express a proto-oncogene in the mammary gland. We show that the biological and genetic properties of mammary tumors initiated by ectopic expression of Wnt-1 are dramatically influenced by the presence or absence of p53. Mammary adenocarcinomas appear earlier in both male and female $p 53-/-$ animals. About half of the tumors arising in $p 53$ heterozygotes show loss of heterozygosity, although they 
are not detected earlier than tumors that retain wild-type p53. p53-deficient tumors differ histologically from p53containing tumors and exhibit several manifestations of genomic instability: aneuploidy in metaphase spreads and genomic regions of increased and decreased DNA sequence copy number as seen by comparative genomic hybridization. These results with transgene-induced cancers in animals extend previous studies with cultured cell lines (Bischoff et al. 1990; Livingstone et al. 1992; Yin et al. 1992) to support a model for p53 as a cell-cycle checkpoint protein whose loss leads to karyotypic instability and cancer.

\section{Results}

Mammary tumors are detected earlier in Wnt-1 transgenic animals lacking a normal p53 gene

To determine the effect of germ-line loss of p53 alleles on Wnt-1-induced mammary tumorigenesis, we crossed p53-deficient mice with Wnt-1 transgenic mice (Wnt-1 $T G$ ). The transgene in the Wnt-1 TG mice mimics a mouse mammary tumor virus (MMTV) insertion at the Wnt-1 locus, with the MMTV long terminal repeat (MMTV LTR) in the opposite transcriptional orientation to the mouse Wnt-1 gene. Previous studies have verified ectopic expression of the Wnt-1 transgene in the mammary gland, accompanied by marked mammary gland hyperplasia in both female and male transgenic animals (Tsukamoto et al. 1988; Kwan et al. 1992). Because of the hyperplasia in the Wnt-1 TG female mammary glands, the animals are unable to nurse their pups. For this reason, we used only Wnt-1 TG males in crosses to the p53-deficient mice. Following the crosses, 12 categories of animals were maintained on the basis of different combinations of genotypes: males and females that carry or lack the Wnt-1 transgene and exhibit one of the three possible $p 53$ genotypes $(+/+,+/-$, or $-/-1$. At least 16 virgin animals in each category were maintained for up to 1 year of age while being monitored weekly for tumors (see Materials and methods).

No mammary adenocarcinomas were observed in any males and females without the Wnt-1 transgene, regardless of p53 genotype. As expected, nontransgenic p53-1 - animals developed nonmammary tumors within the first several months of life and all succumbed to cancer by 9 months of age, consistent with previous experience in other genetic backgrounds (Harvey et al. 1993a, b; Jacks et al. 1994; Purdie et al. 1994). In addition, 4 of 27 p53 +1 - mice developed nonmammary tumors by 1 year of age at a rate similar to that observed previously (Harvey et al. 1993a). No tumors of any kind were observed in the nontransgenic $p 53+1+$ animals.

All of the female mice containing the Wnt-1 transgene developed mammary adenocarcinomas by 41 weeks of age (Fig. 1A). Tumors were detected in Wnt-1 TG $p 53+/+$ females at a median age of 22.5 weeks, a rate similar to that observed previously for Wnt-1 TG females (Tsukamoto et al. 1988; Kwan et al. 1992; Shackleford et al. 1993). Likewise, tumors appeared in the Wnt-1 TG
A

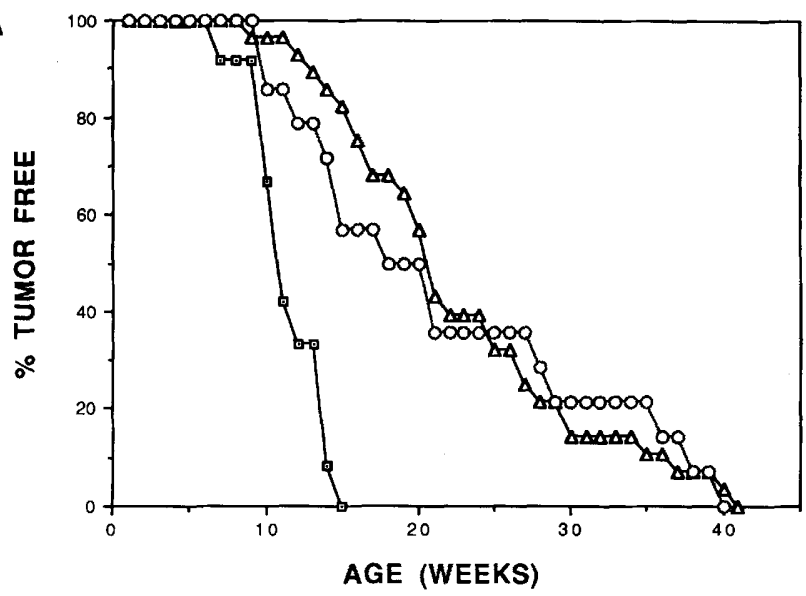

B

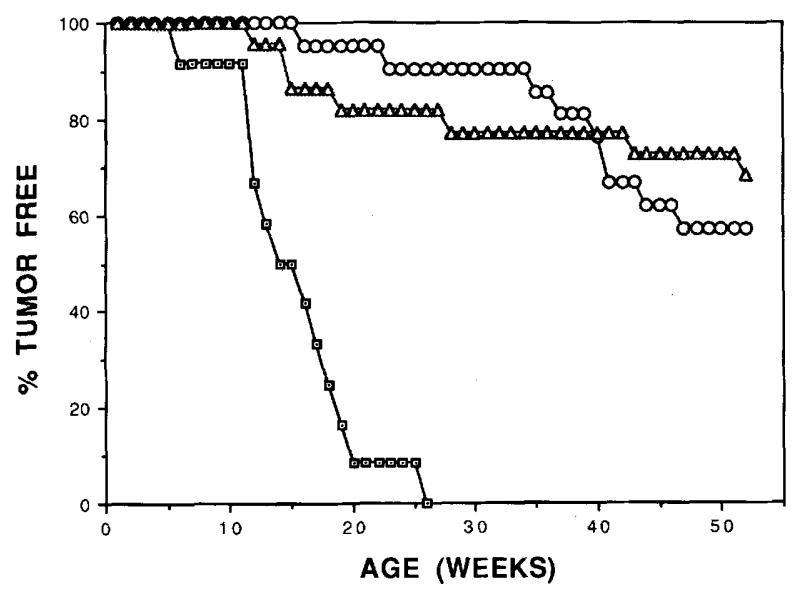

Figure 1. Tumor incidence in Wnt-1 TG mice with wild-type and defective germ-line $p 53$ alleles. The percentage of animals in each group free of palpable tumors $(\sim 0.5 \mathrm{~cm}$ in diam.) was plotted at weekly intervals. (A) Wnt-1 TG females. Sixteen

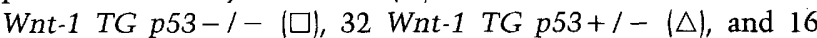
Wnt-1 TG $p 53+1+|O|$ virgin females were monitored for mammary adenocarcinomas. (B) Wnt-1 TG males. Twelve

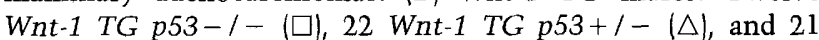
Wnt-1 TG p $53+1+(0)$ males were monitored for mammary tumors up to 1 year of age.

$p 53+/$ - females with a median time of 23 weeks, suggesting that inheritance of a single normal p53 allele does not confer any increase in susceptibility to tumor formation. In contrast, tumors were detected significantly earlier in Wnt-1 TG females with two defective germ-line $p 53$ alleles (Fig. 1A). All of the females with the Wnt-1 TG p53-1 - genotype developed at least one mammary tumor between the ages of 7 and 15 weeks, with a mean time of 11.5 weeks.

Nine of $21(43 \%)$ Wnt-1 TG $p 53+1+$ males and 7 of 22 (32\%) Wnt-1 TG p53+/ - males developed mammary tumors by the age of 1 year (Fig. 1B), proportions slightly greater than observed for Wnt-1 TG males in previous studies (Tsukamoto et al. 1988; Kwan et al. 1992; Shackleford et al. 1993). The Kaplan-Meier plots are not superimposable for these two cohorts, but the rates of ap- 
pearance of tumors were judged to be not significantly different by the generalized Wilcoxon test. The male Wnt-1 TG p53-/- animals, however, displayed a dramatic increase in the rate of appearance of mammary tumors compared with their Wnt-1 TG p53+/ - and Wnt-1 TG p53+1+ counterparts (Fig. 1B). Of 16 of these animals, 12 developed mammary tumors by 6 months of age, whereas the other 4 succumbed to thymic lymphomas within the first 6 months, precluding adequate evaluation for mammary tumors. (These latter animals are not included in Fig. 1B.) For those Wnt-1 TG p53-/males that developed mammary adenocarcinomas, the median time required to form a detectable tumor was 15.5 weeks, nearly as short as the median time for appearance of mammary tumors in Wnt-1 TG p53-/females.

Analysis of the wild-type p53 allele(s) in mammary tumors from Wnt-1 TG p53+/ - and Wnt-1

TG p $53+/+$ mice

p53 allele loss accompanied by point mutation in the remaining $p 53$ allele is a frequent occurrence in human tumors, and we and others have observed loss of the normal p53 allele when mesenchymal tumors and lymphomas arise in $p 53+/-$ mice (Harvey et al. 1993a; Jacks et al. 1994; Purdie et al. 1994). To detect loss of heterozygosity $(\mathrm{LOH})$ of the wild-type allele during the development or progression of mammary tumors in Wnt-1 TG p53+/ - mice, we analyzed the structure of the intact $p 53$ allele in those tumors by Southern blot hybridization. Of 18 tumors from Wnt-1 TG p53+/females, 8 showed virtually complete loss of the remaining wild-type $p 53$ allele, whereas the other 10 tumors contained the normal allele (Fig. 2). In two of these latter tumors, comparison of the hybridization intensities of the normal and mutant p53 alleles suggests that the normal p53 allele is lost from some tumor cells but retained in others. Four tumors from male Wnt-1 TG p53+/ animals were also tested: Two lacked the wild-type allele entirely, and it was underrepresented in a third /data not shown). In tumors from Wnt-1 TG p53+/ - animals that displayed $p 53 \mathrm{LOH}$, comparison of hybridization to the mutant allele and the $p 53$ pseudogene suggested that the mutant allele was not duplicated in tumors from either females and males (Fig. 2; data not shown).
The appearance of $\mathrm{LOH}$ in a high proportion of cells from about half of the tumors in heterozygous animals indicated that cells lacking an intact p53 gene might have a selective growth advantage. However, when we replotted the data shown in Figure lA to separate tumors with $\mathrm{LOH}$ from those without LOH, p53 deficiency did not correlate with the detection of tumors at an earlier age. On average, tumors with $\mathrm{LOH}$ were detected slightly later than those that retained a normal p53 allele (data not shown).

To determine whether point mutations had occurred in the wild-type p53 allele of the Wnt-1 TG p53+1tumors that had not undergone loss of heterozygosity, we sequenced nearly the entire coding region of $p 53$ cDNAs from four of these tumors (see Materials and methods|. Because of the PCR primers used, the first 18 $\mathrm{bp}$ and the last $21 \mathrm{bp}$ of the $p 53$-protein coding sequences could not be determined, but the rest of the sequence was wild-type (data not shown).

Southern blot analyses and previous sequencing of $p 53$ cDNAs derived from mammary tumor RNAs from Wnt-1 TG mice (V. Pecenka and H.E. Varmus, unpubl.) failed to reveal any changes in the $p 53$ gene when both p53 alleles are intact in the germ line.

\section{All of the mammary tumors are adenocarcinomas, but they differ in the degree of fibrosis depending on p53 status}

We performed standard histopathological examination on most of the mammary tumors in the study. A total of 40 tumors from female mice and 18 tumors from male mice were evaluated for general histoarchitecture and mammary tumor classification, without prior knowledge of p53 genotype. The majority of the tumors in female mice $(29 / 40)$ and in male mice (11/18) were type-B mammary adenocarcinomas (Sass and Dunn 1979). This pathological type was the most common regardless of the $p 53$ genotype or sex of the animal. The rest of the tumors were either papillary cystic adenocarcinomas or type-A adenocarcinomas, two morphological variants that are more differentiated and less aggressive than the type $B$ adenocarcinomas.

Extensive fibrosis was observed in most of the tumors arising in the Wnt-1 TG p53+/+ female mice (Fig. 3A). In contrast, tumors from Wnt-1 TG p53-/ - females did
Figure 2. Loss of the wild-type allele in some Wnt-1 TG p53+1- tumors. Each lane contains $10 \mu \mathrm{g}$ of tumor DNA from individual female Wnt-1 TG p53+1- tumors cleaved with BamHI. After agarose gel electrophoresis, the DNAs were transferred to nylon and hybridized to the p53 cDNA exon 2-6 probe. The relevant $B a m H I$ fragments are $\sim 5 \mathrm{~kb}$ (from the wild-type allele), $6.5 \mathrm{~kb}$ (from the null allele), and $10 \mathrm{~kb}$ (from the $p 53$ pseudogene). Lane $\mathrm{N}$ contains tail DNA from one of the tumor-bearing animals.

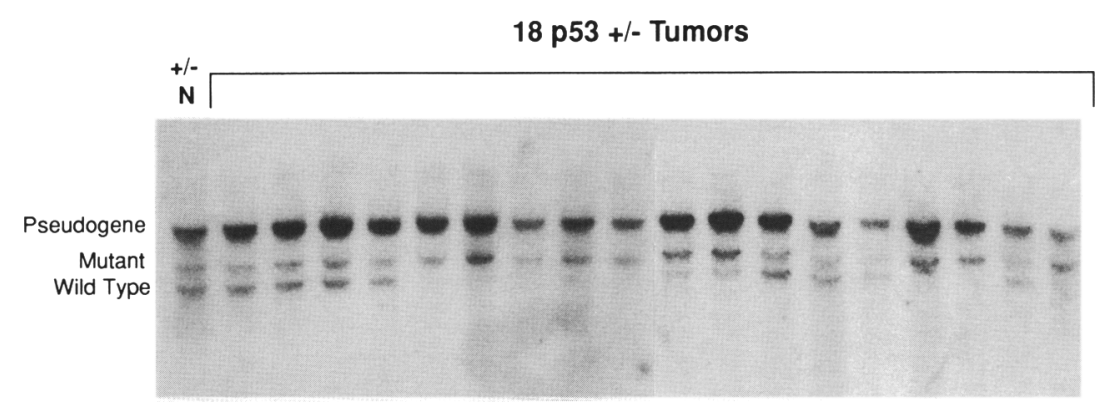



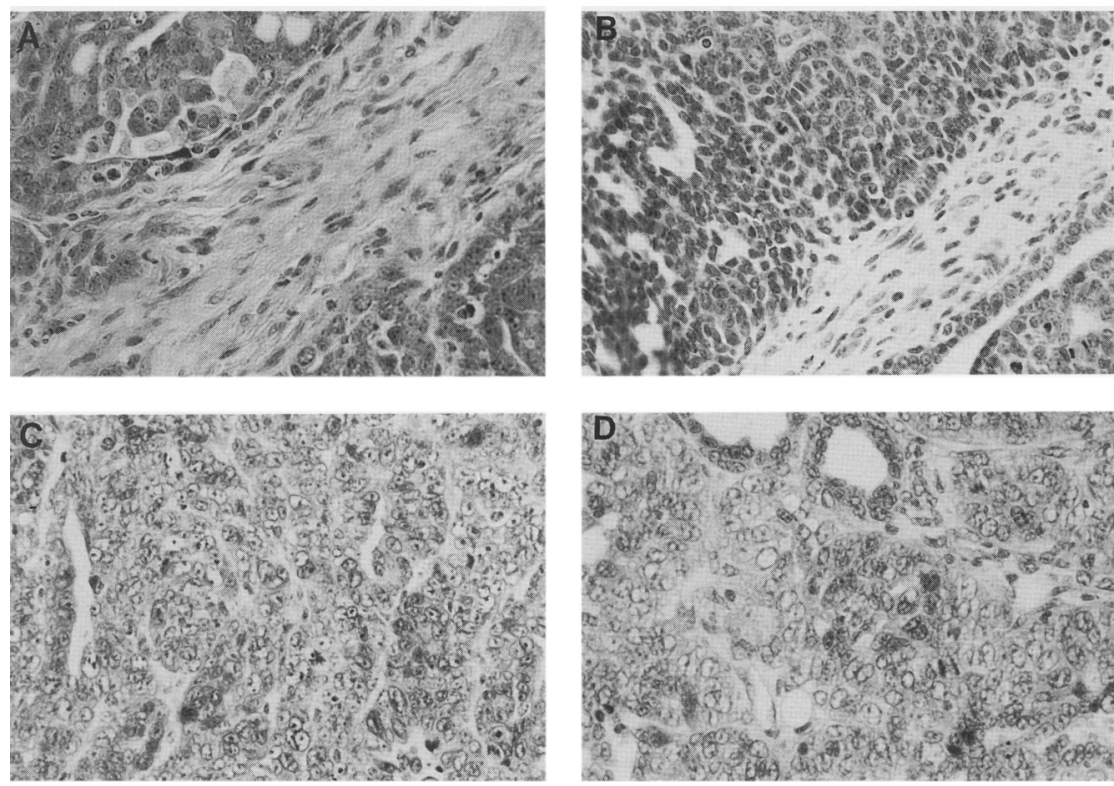

Figure 3. Fibrotic and nonfibrotic histopathology in mammary tumors from mice with different $p 53$ genotypes. (A) Histopathology section of a tumor from a Wnt-1 TG p53+1+ female. (B) Histopathology section of a tumor that retained the wildtype $p 53$ allele from a Wnt-1 TG p53+/female. $(C)$ Histopathology section from a tumor that had lost the wild-type p53 allele from a Wnt-1 TG p53+/ - female. (D) Histopathology section of a tumor from a Wnt-1 TG p53-/ - female. All slides are stained with hematoxylin and eosin. Magnification, $94 \times$. not exhibit significant fibrosis and frequently contained multiple mitotic cells and signs of anaplasia (Fig. 3D). Similar trends were apparent in the smaller collection of tumors from male mice (data not shown). Tumors from Wnt-1 TG p53+1 - females varied with respect to the degree of fibrosis and number of mitotic cells. When some of these tumors were assessed for loss of the wildtype allele, as illustrated in Figure 2, retention of the wild-type allele correlated quite well with more extensive fibrosis and infrequent mitotic cells (Fig. 3B,C). Of 19 mammary adenocarcinomas with wild-type $p 53$ that were examined ( $p 53+/+$ and $p 53+/-$ without $\mathrm{LOH})$, 14 showed extensive fibrosis. In contrast, in tumors without wild-type p53 (p53-/- and $p 53+/-$ with $\mathrm{LOH}$ ), only 1 of 12 tumors exhibited fibrosis. These findings suggest that significant biological differences may exist between those tumors that produce and those that do not produce $\mathrm{p} 53$ protein.

\section{Metaphase spreads reveal a tendency to aneuploidy in p53-deficient mammary tumor cell explants}

Earlier studies have revealed that p53-deficient cells in culture exhibit genomic instability as manifested by aneuploidy and susceptibility to gene amplification (Livingstone et al. 1992; Yin et al. 1992). To determine whether partial or complete loss of $p 53$ predisposes cells to aneuploidy during tumorigenesis in vivo, we examined the karyotypes of cultured cells from five mammary tumors from Wnt-1 TG p53+1+ females, four mammary tumors from Wnt-1 TG p53+/ - females, and six mammary tumors from Wnt-1 TG p53-/ - females. Karyotyping was performed on cells grown in culture for 24-48 $\mathrm{hr}$ after dispersion from mammary tumors. Cultures were incubated with Colcemid, fixed, and stained according to standard procedures (Fig. 4I,J), and the chromosomes of 25-50 metaphase spreads were counted for each tumor. Any chromosome count other than 40 (the mouse diploid chromosome number) was considered aneuploid. Chromosome numbers are given in Figure 4 for all cells analyzed from eight representative tumors. Overall, the results demonstrate that the absence of $p 53$ predisposes tumor cells to aneuploidy.

Cells from Wnt-1 TG p53+ / + tumors were typically exactly diploid (Fig. 4A,B). In cells from five such tumors, $>70 \%$ of the metaphase spreads were diploid, and the occasional deviant cells were usually exactly tetraploid or very nearly diploid (Fig. 4A,B; data not shown).

Wnt-1 TG p53-1 - tumors fell into two groups on the basis of karyotyping (Fig. 4C,D). Three tumors yielded a very high percentage of cells with grossly abnormal karyotypes, mostly subtetraploid (e.g., Fig. 4C). As is evident from the metaphase spread illustrated in Figure 4J, cells from some of these tumors demonstrated dicentric chromosomes and chromosomes with homogenously staining regions, suggesting gene amplification, in addition to increased chromosome numbers. The other three tumors from Wnt-1 TG p53 - / - animals displayed karyotypes similar to those from tumors with a wild-type $p 53$ genotype (e.g., Fig. 4D). In one case, however, $>20 \%$ of the cells were tetraploid, whereas in another case nearly $30 \%$ of the cells had 39 chromosomes (data not shown). Thus, a deficiency of p53 strongly predisposes cells in mammary tumors to aneuploidy, but is not sufficient to produce it.

We also inspected metaphase spreads from four tumors arising in Wnt-1 TG p53 $+1-$ animals (Fig. 4E-H). The karyotypes of cells from two of these tumors were not distinguishable from tumors arising in a normal $p 53$ background. Over $80 \%$ of metaphases were diploid, and $\sim 10 \%$ were tetraploid with 80 chromosomes (Fig. 4G, H). One of these two tumors retained the normal p53 allele in most or all cells, but the other had undergone loss of heterozygosity, again demonstrating that the absence of 
Donehower et al.

Figure 4. Karyotypes of cultured tumor cells from Wnt-1 TG mice with intact or defective p53 alleles. Metaphase spreads were prepared as described previously (Aldaz et al. 1992). Chromosome numbers were determined in at least 25 different spreads from cultured cells from each tumor. Percentages of tumor cells with given chromosome numbers from representative tumors are shown. $(A, B)$ Representative Wnt-1 TG p53+1+ tumors; $(C, D)$ representative Wnt-1 TG p53-1- tumors; (E,F) tumors from Wnt-1 TG p53+1mice with loss of wild-type p53 allele; $|G|$ tumor from Wnt-1 TG p53+1- mouse with retention of the wild-type $p 53$ allele; (H) tumor from Wnt-1 TG $p 53+1-$ mouse with $\mathrm{LOH}_{;}(I)$ typical metaphase spread of a tumor cell with a diploid karyotype from a Wnt-1 TG p53+1+ female photographed after Giemsa trypsin staining; $(I)$ typical metaphase spread of tumor cell with a hypotetraploid karyotype from a Wnt-1 TG p53-/ - tumor photographed after DAPI staining. A dicentric chromosome is indicated by the arrowhead.
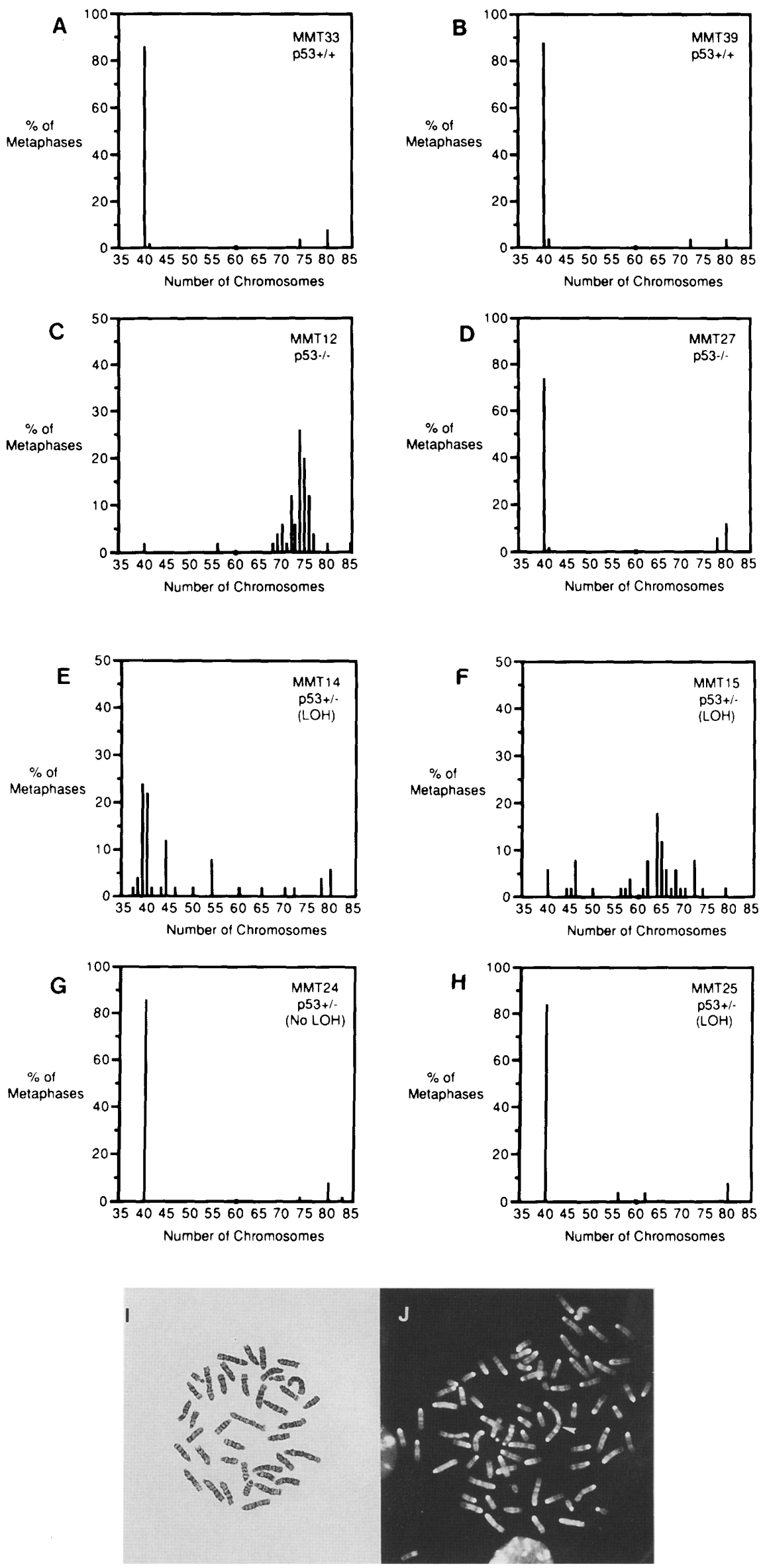
p53 from mammary tumor cells does not mandate aneuploidy. The other two Wnt-1 TG p53+1- tumors showed extensive aneuploidy, with a wide distribution of chromosome numbers, suggesting that the tumor cell population was heterogeneous and continuing to evolve at the time the animal was sacrificed (Fig. 4E,F). Both of these tumors had lost the wild-type $p 53$ allele from the majority of cells, as judged by Southern blotting (data not shown), suggesting that the absence of p53 contributes to karyotypic instability.

Comparative genomic hybridization and Southern blot hybridization provide further evidence of genomic instability in p53-deficient tumors

To complement the cytogenetic data and to identify recurring regions of chromosomal change in the Wnt-1 TG mammary tumors, we employed the comparative genomic hybridization (CGH) technique (Kallioniemi et al. 1992). This procedure detects regions of increases and decreases in DNA copy number throughout the entire genome of a tumor cell. This is achieved by differential fluorescent labeling of total genomic DNA samples from a tumor and from normal tissue. These two DNAs are hybridized to metaphase spreads of normal mouse chromosomes. Chromosomal regions showing losses and gains in the tumor can be recognized as decreases and increases, respectively, in the intensity of fluorescence from the tumor DNA relative to that from the normal DNA. Two examples of the results of such hybridizations are illustrated in Figure 5. In the first example, the tumor shows many changes by $\mathrm{CGH}$ (Fig. $5 \mathrm{~A}, \mathrm{~B})$, and in the other, a single change is observed (Fig. $5 \mathrm{C}, \mathrm{D}$ ). The abnormalities from all of the tumors examined are summarized in Table 1.

Four of the six Wnt-1 TG p53+/+ mammary tumors examined by $\mathrm{CGH}$ had no detectable abnormalities, and the other two had only a single chromosomal alteration. Similarly, two of four tumors from $p 53$ heterozygous mice that retained the wild-type $p 53$ allele did not have detectable abnormalities, whereas two others displayed one or three subchromosomal decreases in DNA copy number. These findings are consistent with the low level of aneuploidy observed in such tumors by standard karyotyping.

In contrast, all seven of the Wnt-1 TG p53-/ - tumors showed at least one chromosomal abnormality, and some exhibited multiple changes. Furthermore, the eight tumors that lost the wild-type p53 allele while developing in Wnt-1 TG $p 53+/-$ mice showed the most chromosomal instability. Seven of the tumors displayed at least three regions of DNA gain or loss, and one tumor (W166; Fig. 5A,B) had 10 detectable genetic changes. The Wnt-1 TG p53+ / - tumors with p53 LOH averaged 4.2 detectable chromosomal abnormalities per tumor. In contrast, tumors that developed in Wnt-1 TG p53+/+ mice or in Wnt-1 TG $53+/$ - without LOH averaged only 0.33 and 1.0 abnormalities per tumor. An average of 1.7 chromosomal abnormalities was observed in the tumors from animals with the Wnt-1 TG p53-/- geno- type. Four of the p53-deficient tumors with CGH abnormalities, two from p53-1- animals and two from p53+/ - animals with $\mathrm{LOH}$, were also examined by standard karyotyping. One of each genotype revealed a high level of aneuploidy (see footnotes in Table 1).

Several recurring chromosomal changes were noted by CGH. As expected, many of the Wnt-1 TG p53+/ - tumors that had lost their wild-type allele showed a loss of DNA from chromosome 11, which contains the mouse p53 locus (Czosnek et al. 1984; Rotter et al. 1984). Other recurring alterations in the tumors included DNA losses from chromosome 4 (three tumors), chromosome 8 (four tumors), chromosome 9 (four tumors), chromosome 13 (five tumors), and the $\mathrm{X}$ chromosome (five tumors). Increases in DNA were also observed for chromosome 7 (two tumors) and chromosome 10 (two tumors).

As an adjunct to $\mathrm{CGH}$, we used genomic Southern blot hybridization with gene-specific probes to ask whether known proto-oncogenes were amplified in Wnt-1 TG p53-deficient tumors. Probes for three loci known to be amplified in some human mammary tumors-c-myc (Escot et al. 1986), neu (Slamon et al. 1987), and int-2/FGF3 (Lidereau et al. 1988) - were used to test tumor DNAs from 18 Wnt-1 TG p53-/ - animals and from 6 Wnt-1 TG p53+/ - animals whose tumors had lost the wildtype $p 53$ allele (Fig. 6A; data not shown).

In tumor B from animal W177, the int-2/FGF3 locus was increased to about six to eight copies per cell. This change was consistent with the CGH profile for tumor 177B, which showed only one abnormality: increased representation of DNA from the distal portion of mouse chromosome 7, the chromosomal location of int-2/FGF3 (Fig. 5C,D). A second tumor that arose independently in this animal $(177 \mathrm{~A})$ did not show these changes by $\mathrm{CGH}$ or Southern blot hybridization (Table 1; Fig. 6A).

In some human breast tumors, the int-2/FGF3 region is amplified, and the amplified domain includes the linked genes hst/FGF4 and PRAD-1/cyclin D1. Because $P R A D-1 /$ cyclin $D 1$ is the only one of these three loci expressed in such tumors, the cyclinD1 gene rather than either FGF gene is believed to be contributing to carcinogenesis (Lammie et al. 1991). However, several kinds of experiments suggest that ectopic expression of $F G F$ genes can synergize with Wnt-1 to promote mouse mammary tumors (Peters et al. 1986; Kwan et al. 1992; Shackleford et al. 1993). When we measured int-2/FGF3, hst/ FGF4, or PRAD-1/cyclin D1 RNAs in tumor W177B and in several other tumors, int-2/FGF-3 RNA was abundant in W177B but undetectable in other tumors (Fig. 6B). Equally low levels of $h s t / F G F 4$ and PRAD-1/cyclin D1 RNA were observed in all of the samples (data not shown). These findings suggest that activated expression of int-2/FGF-3 (by an unknown mechanism) accompanied by amplification of the gene (perhaps facilitated by p53 deficiency), participated in the oncogenic process in tumor 177B.

\section{Discussion}

Abnormalities of $p 53$ are common in human breast can- 

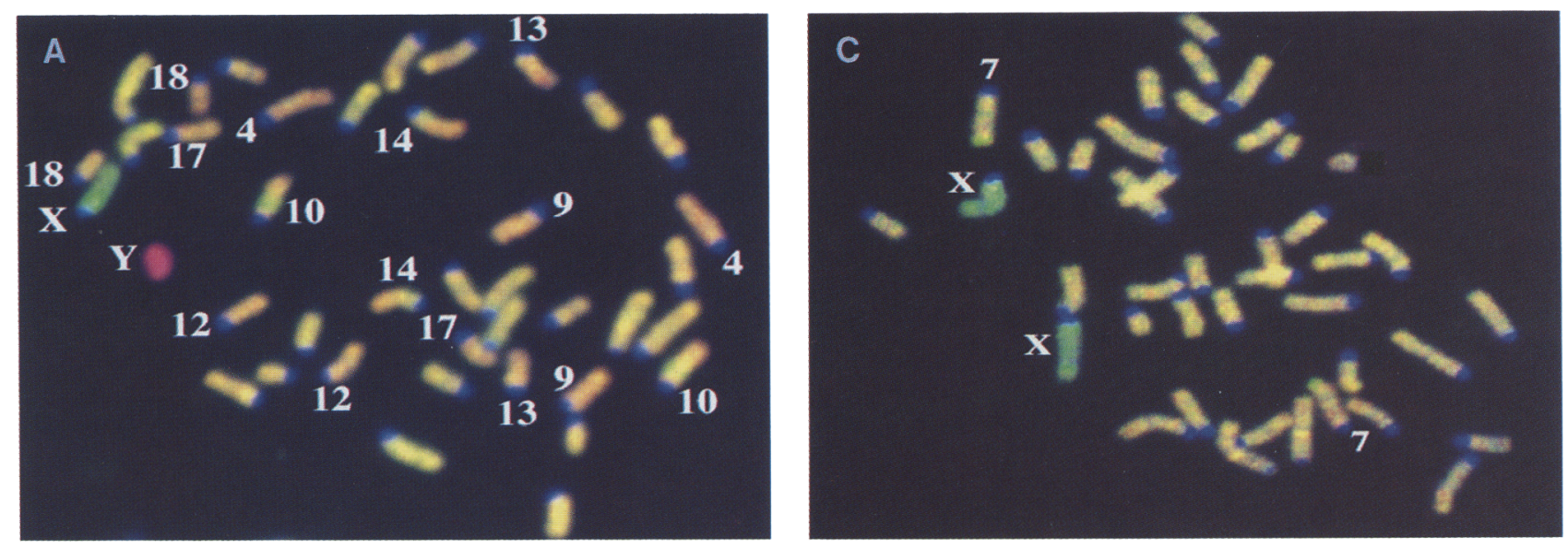

B
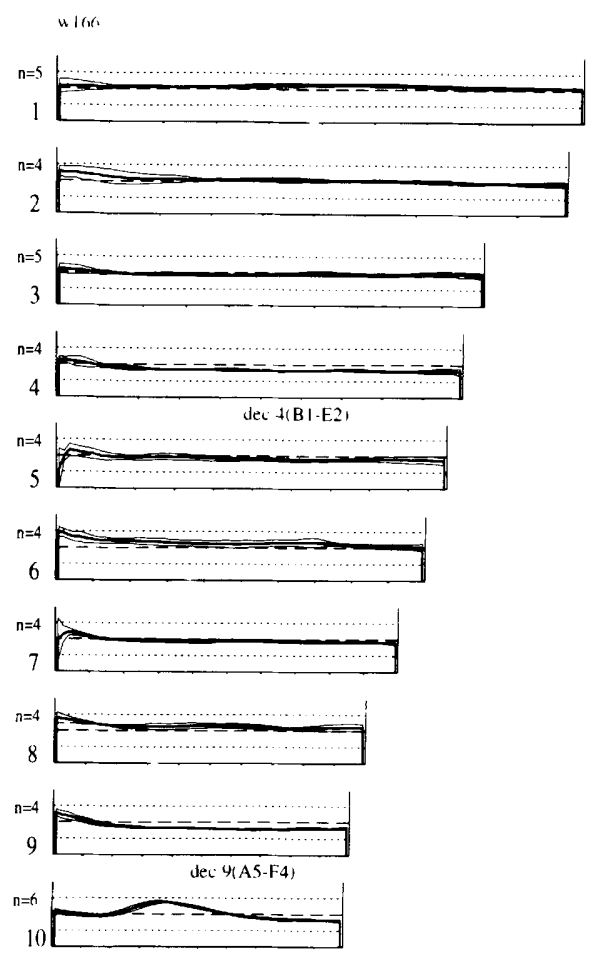

inc l(M B $1-\mathrm{B} 5)$ dec Ith(Cl-D3)
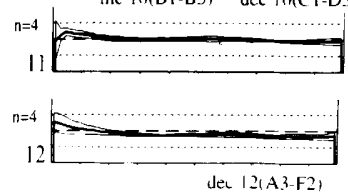
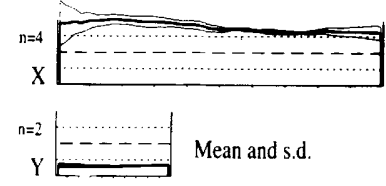

D
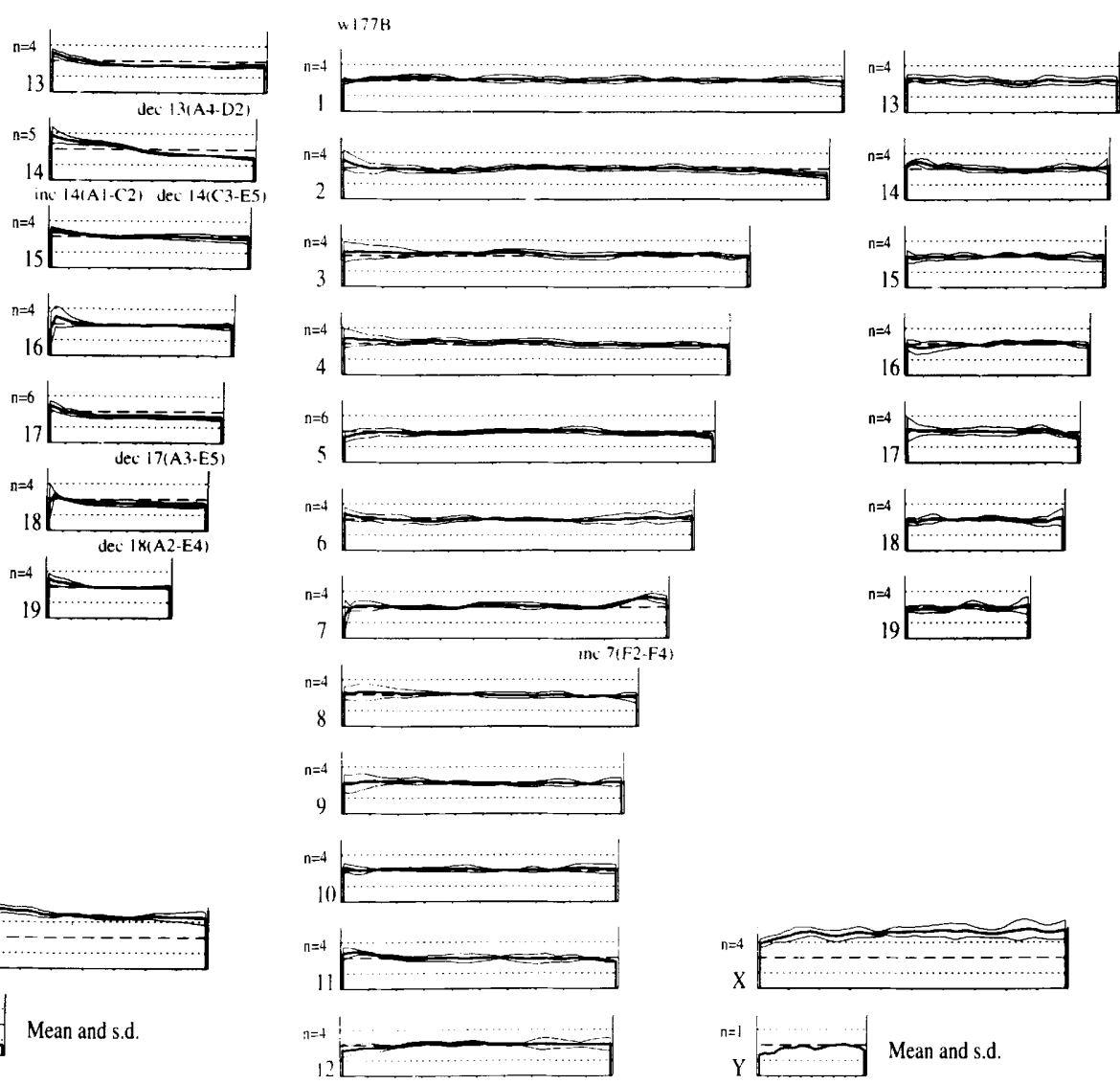

Figure 5. Representative comparative genomic hybridization images and fluorescence ratio profiles. (A) Composite digital image from CGH analysis of tumor W166 (Wnt-1 TG p53+/- tumor that had lost the wild-type $p 53$ allele). Tumor genomic DNA hybridization signal is displayed in green, normal genomic DNA in red, and the normal male metaphase target chromosomes in blue. Regions of relatively green fluorescence indicate increased copy number of these sequences in the tumor, and red regions indicate decreases of copy number relative to the average for the tumor. Blue regions of the target chromosomes contain repeated satellite sequences where hybridization is blocked by unlabeled $\mathrm{C}_{0} \mathrm{t}-1$ DNA. Those chromosomes containing regions of variant copy number are labeled in the image. The specimen is from a female mouse, and the normal DNA is male so that the X chromosome appears green and the $\mathrm{Y}$ chromosome appears red. $(B)$ Profiles of the green to red fluorescence intensity for each of the chromosomes from tumor W166. The heavy lines show the average of profiles from several chromosomes of each type (indicated by the $n$ value next to each profile); the thin lines show $+/ \pm 1$ S.D. from the mean. The lengths of the profiles are arbitrarily normalized and are not accurately proportional to chromosome length. The regions of variant copy number are indicated under the individual profiles and correspond to those shown in Table $1 .(C)$ Composite digital image from the analysis of a Wnt-1 TG p53-/ - tumor, W177B. (D) Ratio profiles of tumor W177B. The only significant variation is on the distal portion of chromosome 7 corresponding to the green region of the image in $C$. 
Table 1. Comparative genomic hybridization of tumor DNAs

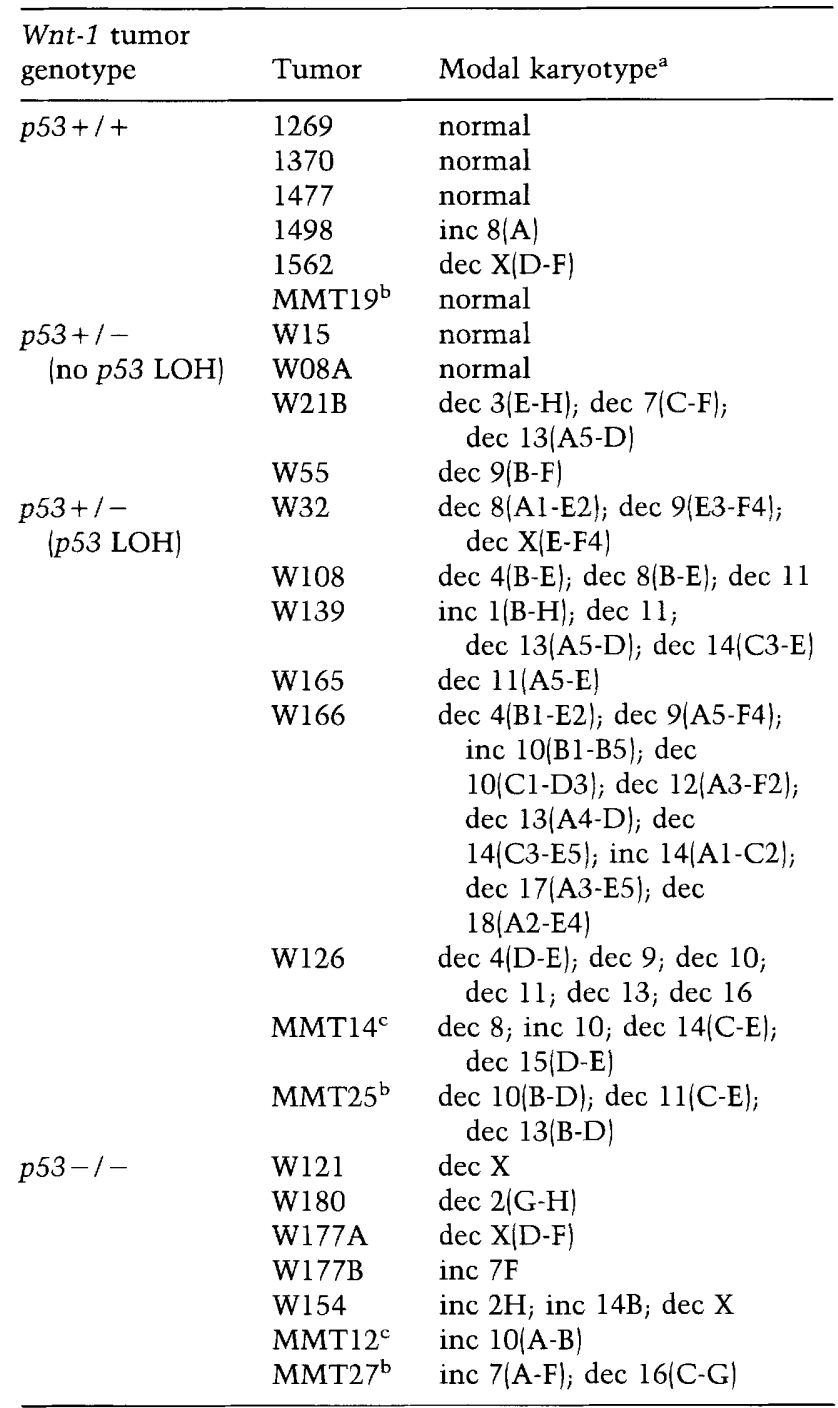

Tumor DNAs were analyzed by comparative genomic hybridization (Kallioniemi et al. 1992). Chromosomal abnormalities are indicated dec for DNA copy number decreases and inc for DNA copy number increases, followed by the mouse chromosome number. Subchromosomal regions affected by these changes are indicated in parentheses by uppercase letters. Each letter represents a band visible by DAPI staining; A is the band closest to the centromere.

${ }^{\mathrm{b}}$ Tumor diploid by karyotyping.

'Tumor aneuploid by karyotyping.

cer (Greenblatt et al. 1994), yet mammary tumors have rarely been encountered in mice with null alleles at the p53 locus (Donehower et al. 1992; Jacks et al. 1994; Purdie et al. 1994) or with mutant p53 transgenes (Lavigueur et al. 1989). To examine the role of p53 in mammary tumorigenesis in an animal model, we have introduced a Wnt-1 transgene, known to induce mammary hyperplasia and a strong predisposition to mammary cancer, into mice bearing one or two copies of a targeted null muta- tion of $p 53$. Two major findings with the progeny of this cross strongly support our conclusion that a deficiency of p53 influences the formation of mammary tumors in the presence of the Wnt-1 transgene: (1) Tumors arise much earlier in animals that do not inherit an intact $p 53$ gene (Fig. 1), and (2) tumors that develop in animals constitutively heterozygous at the $p 53$ locus often show loss of heterozygosity (Fig. 2), implying a selective growth advantage for mammary tumor cells in which no functional $p 53$ gene remains.

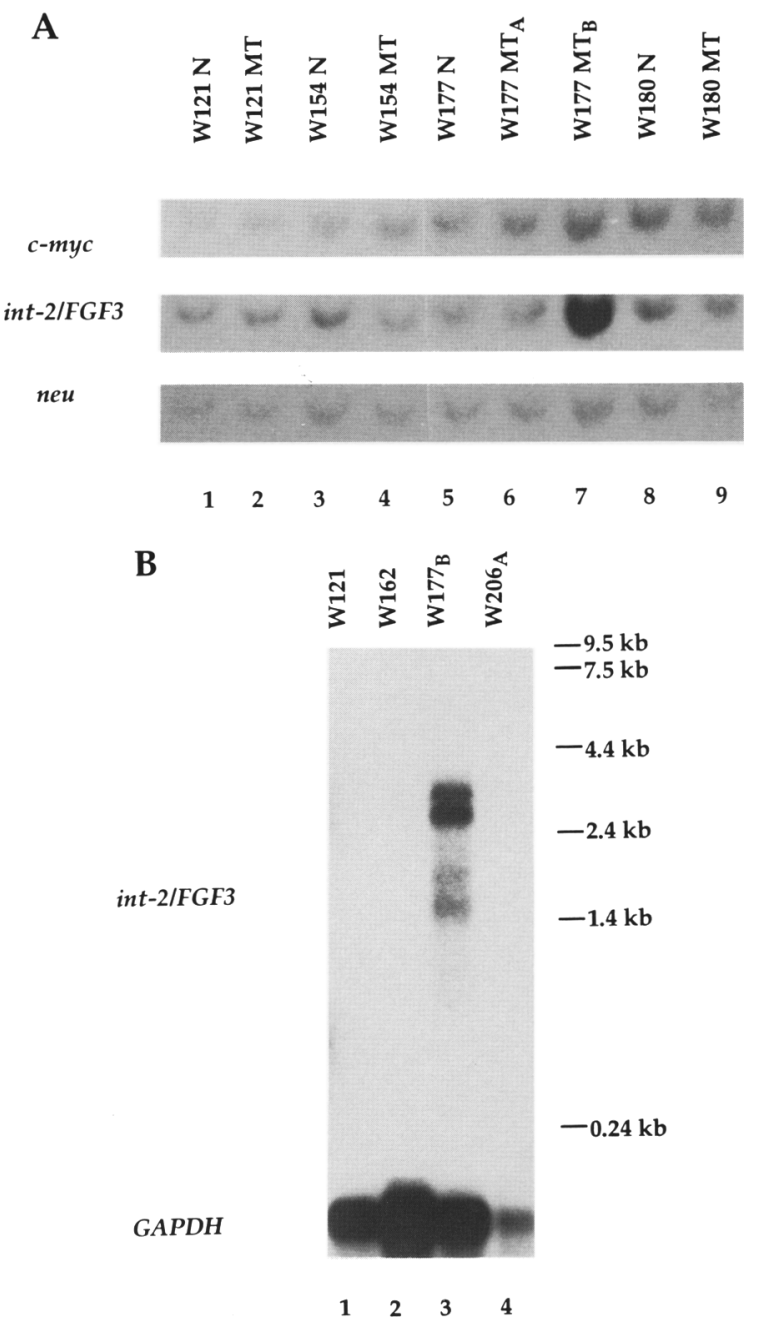

Figure 6. Southern and Northern blotting analyses of Wnt-1 TG p53-1- mammary tumors. (A) Gene amplification of the int-2/FGF3 locus in Wnt-1 TG p53-/ - tumor W177B. Southern blotting was performed with multiple probes on paired samples from Wnt-1 TG p53-/ - tumors. At the top of each lane, the mouse identification number is given: $(N)$ normal tail DNA; (MT), mammary tumor DNA. Subscript letters distinguish independently arising tumors in a single animal. The gene from which each probe is derived is given at left. $(B)$ Overexpression of int-2/FGF3 in Wnt-1 TG p53-/ - mammary tumor W177B. Northern blotting of RNA from Wnt-1 TG p53-/ - tumors was performed with multiple probes. The gene from which each probe is derived is given at left, and RNA sizing is at right. 
Three striking correlations have emerged from our efforts to understand the contribution that a deficiency of p53 might make to the oncogenic process in these animals: (1) We noted histopathological differences between tumors that retained and those that lacked a $p 53$ gene. p53-Deficient tumors were, in general, less fibrotic, and contained more mitotic and anaplastic cells; (2) aneuploidy was frequent in cells derived from tumors lacking p53 and much less common in tumor cells that retained p53; and (3) relative gains and losses of chromosomal DNA, as measured by $\mathrm{CGH}$, were more common in tumors that lacked p53, especially in those p53-deficient tumors resulting from loss of a wild-type $p 53$ gene in a heterozygous background. These findings imply that there are at least two pathogenic routes by which mammary tumors can arise in Wnt-1 transgenic mice. In one, p53 continues to function, tumor cells show little aneuploidy or chromosomal rearrangement, and the tumors contain extensive fibrosis. In the other, p53 function is lost, the tumor cell genome is destabilized, and the tumors are minimally fibrotic.

\section{p53 deficiency and the kinetics of tumorigenesis}

We initiated the experiments described here in hopes of understanding the multistep process of carcinogenesis in greater detail. Our results have provoked at least two perplexing questions about the number, timing, and functional consequence of the events in mammary tumorigenesis: (1) Why do tumors appear relatively early in p53-deficient mice? and (2) why do tumors fail to appear early in heterozygous mice when the normal p53 gene has been eliminated? We have considered possible answers to these questions in the context of two models that posit cell-autonomous and non-cell-autonomous functions for p53 protein (Fig. 7A,B).

Loss of one or more of the cell-autonomous functions previously proposed for the $p 53$ gene product might foster the development of a tumor and thereby help to explain the early onset of tumors in Wnt-1 TG p53-1animals (Fig. 7A): (1) Loss of cell-cycle control and accompanying genomic instability (Livingstone et al. 1992; Yin et al. 1992; Harvey et al. 1993c) might favor the more rapid accumulation of additional mutations necessary for tumor development; (2) changes in control of p53dependent transcription (Farmer et al. 1992; Kern et al 1992) might affect cell growth rates or other cell processes; (3) resistance to apoptosis (Yonish-Rouach et al. 1991; Clarke et al. 1993; Lowe et al. 1993a,b) might increase cell numbers during tumor growth, because p53-

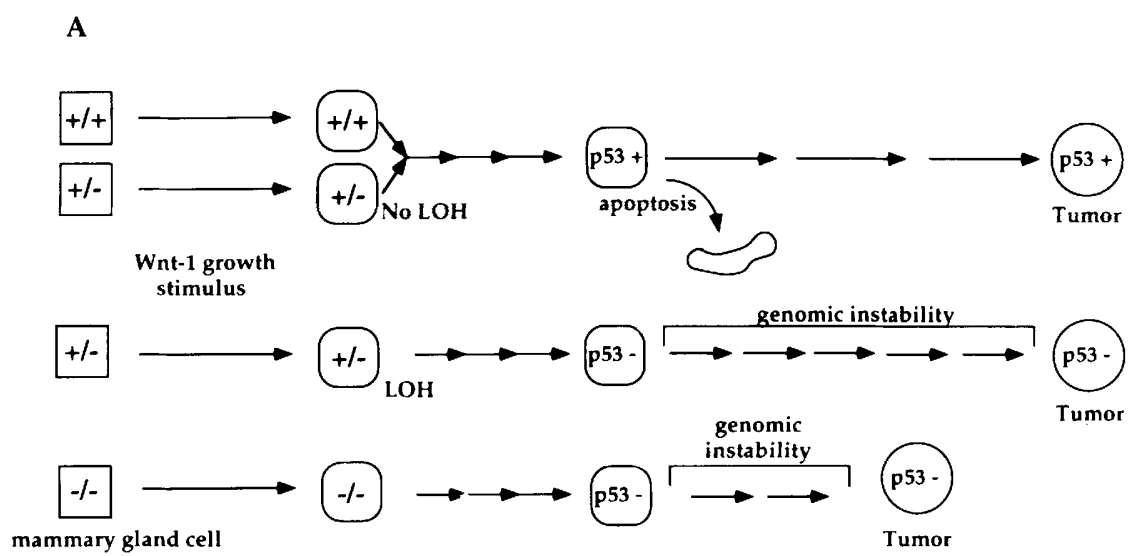

B
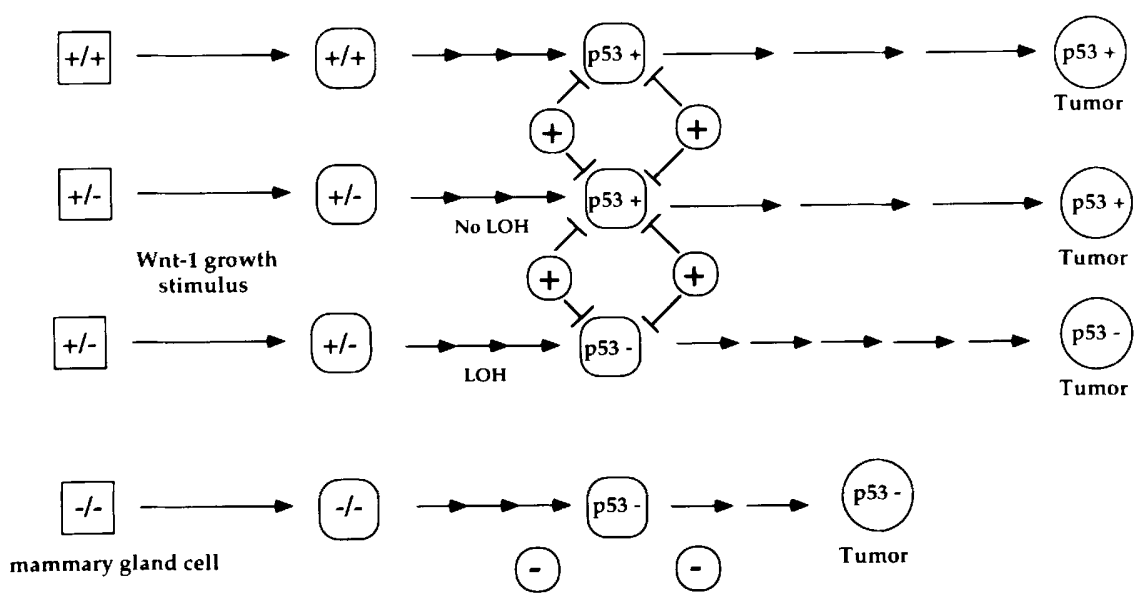

Figure 7. Multistep models of mammary tumorigenesis in Wnt-1 TG p53 mice. (Squares) Normal mammary gland epithelial cells; (squares with rounded edges) preneoplastic cells; and (circles) the dominant cell population in a tumor. Arrows between cells indicate genetic or epigenetic changes that occur during tumor cell initiation and progression. (A) The cell-autonomous model. Initially in all Wnt-1 TG mice, ectopic expression of Wnt-l protein in normal mammary gland cells induces polyclonal hyperplastic growth. Further growth stimulation by Wnt-1 accompanies additional genetic or epigenetic changes that produce clonal tumor growth. In this model the rate of progression depends on the $p 53$ status of the initiated cell. Cells that retain wild-type $p 53$ produce tumors at a delayed rate, possibly because of a lower frequency of genetic change and p53-mediated apoptosis. ( $B)$ The non-cell-autonomous model. In this model tumor cell progression is regulated in part by events extrinsic to that cell that will give rise ultimately to a tumor. The p53 genotype of the host animal, not the genotype of the nascent tumor cell, determines the speed of tumor formation. It is hypothesized that surrounding cells that have wild-type $p 53(p 53+/+$ and $p 53+/-$ animals) inhibit expansion of the tumor cell clone, whereas in $p 53-/-$ animals this inhibitory effect does not occur. Fewer genetic changes may be necessary for the nascent tumor cell in p53-1- animals to form a tumor because of the reduction of inhibition by surrounding cells. 
mediated programmed cell death no longer counterbalances Wnt-1-stimulated proliferation. Although we have provided considerable support for the first of these three explanations, we have not yet tested directly for contributions by the latter two. Moreover, we have identified only a single specific mutation, amplification of int-2/ $F G F-3$ in tumor $177 \mathrm{~B}$, that is likely to participate in carcinogenesis, despite abundance evidence for genomic instability.

These proposed effects of p53 on cell growth are not, however, sufficient to account for the observation that p53 LOH failed to accelerate the development of tumors in Wnt-1 TG p53+/ - animals. Perhaps the simplest explanation for this observation is that $p 53 \mathrm{LOH}$ is a late event in this tumorigenesis model. This hypothesis can be tested further by comparison of the frequency of $p 53$ $\mathrm{LOH}$ as a function of tumor size. A non-cell-autonomous model is presented in Figure $7 \mathrm{~B}$ to account for the paradoxical finding that Wnt-1 TG p53+/ - tumors with $\mathrm{LOH}$ display more evidence of genomic instability than Wnt-1 TG p53-/ - tumors. Wnt-1 TG p53-/ - mice might develop mammary tumors earlier than their Wnt-1 TG p53+/ - and Wnt-1 TG p53+/+ counterparts because of a permissive environment afforded by p53-/ - cells surrounding nascent tumor cells. Conversely, p53-containing cells that surround neoplastic cells, including p53-deficient tumor cells, might provide an inhibitory influence and retard growth of the tumor clone, demanding that the clone undergo further mutations to overcome the inhibition.

The idea that normal cells surrounding a transformed cell can influence its growth potential has been demonstrated previously both in vitro and in vivo, as assayed by focus formation in primary rodent fibroblasts (Land et al. 1983) and by tumorigenic potential of mixtures of normal and preneoplastic mammary cells (Medina et al. 1978). Such a model implies that wild-type p53 may have an extracellular inhibitory role in growth control, in addition to its well-characterized intracellular effects. For example, wild-type p53 was shown to stimulate expression of thrombospondin-1, a potent inhibitor of angiogenesis (Dameron et al. 1994).

\section{p53 and genomic stability}

Our findings of aneuploidy and CGH abnormalities in mammary tumors in conjunction with p53 deficiency are consistent with previous reports that the lack of p53 predisposes cultured cells to aneuploidy and amplification of selectable genes (Livingstone et al. 1992; Yin et al. 1992). By extending these observations to a tumor model in an intact animal, we provide support for the hypothesis that p53 deficiency contributes to carcinogenesis by promoting chromosomal rearrangements that favor tumor cell growth. But the findings also emphasize the importance of two largely unresolved questions.

1. What is the mechanism by which p53 protects a cell from genomic instability? p53 is believed to defend cells from premature entry into the $S$ phase of the cell cycle, an idea that has been especially well-documented after exposure of cells to genotoxic agents (Kastan et al. 1991, 1992; Lu and Lane 1993). Failure to block passage through the cell cycle could result in permanent genetic change if the genome has been assaulted by radiation or chemical mutagens, without sufficient opportunity for repair. Deficiency of p53 per se does not produce chromosomal abnormalities because mice carrying targeted germ-line mutations of $p 53$ can develop normally despite a total absence of p53 protein (Donehower et al. 1992; Jacks et al. 1994; Purdie et al. 1994). Also, some mammary tumors from p53-deficient animals are composed largely of diploid cells with relatively few abnormalities seen by CGH (Fig. 5). However, the absence or loss of p53 causes a predisposition to genomic instability in established cell lines and in cultured fibroblasts from p53deficient animals (Bischoff et al. 1990; Livingstone et al. 1992; Yin et al. 1992; Harvey et al. 1993c), and we have observed a higher frequency of aneuploidy and abnormalities detectable with CGH in p53-deficient tumors (Figs. 4 and 5; Table 1). The factors that provoke genomic instability in p53-deficient cells remain unknown. Their identity might be useful in considering both the origins and treatment of cancers.

2. What are the specific genetic consequences of $p 53$ deficiency that promote the growth of tumor cells? In at least one instance, tumor 177B, we were able to provide some answer to this question, because the amplified DNA included a gene, int-2/FGF-3, that is known from several other kinds of experiments, to collaborate with Wnt-1 when expressed ectopically in mammary tissue (Peters et al. 1986; Kwan et al. 1992; Shackleford et al. 1993). The increases and decreases of several other chromosomal domains may also be functionally important, because the changes were encountered in multiple tumors or because the domains are syntenic with those implicated in human or experimental tumors. Recurring decreases in DNA occurred on chromosomes 4, 8, 9, 11, 13 , and $\mathrm{X}$, arguing that the genomic instability in this model is at least partially nonrandom and may represent genetic events that provide a selective growth advantage during tumor progression. The role such genomic losses play in the progression of mammary cancer remains to be elucidated. However, the largely normal karyological and CGH patterns observed in tumors that retain p53 show that the abnormalities detectable with these methods are not absolutely required for Wnt-1-promoted tumorigenesis. In addition, it should be noted that increased genomic instability did not necessarily correlate with accelerated tumorigenesis, as the Wnt-1 TG $p 53+1$ - tumors with LOH displayed the greatest numbers of karyotypic abnormalities but did not show an increase in rate of formation in comparison to Wnt-1 TG p53+/ + tumors and Wnt-1 TG p53+/ - tumors without LOH. This lack of correlation suggests that genomic instability may provide a selective advantage during tumor progression, but does not necessarily affect the rate at which the tumors appear. 


\section{Further definition of multistep mammary tumorigenesis}

Our work demonstrates that the proto-oncogene Wnt-1 and the tumor suppressor gene p53 can collaborate to produce mammary cancers in mice, but it is evident from the kinetics of appearance of new tumors that other events are required. We presume these to be mutations, at least some of which are represented by the genomic abnormalities observed by CGH. Moreover, we do not know how many mutations are required, how many oncogenic combinations of mutations are possible /even in the limited context of a Wnt-1-stimulated, hyperplastic mammary gland), or what constraints are placed on the order in which the mutations occur.

Multistep carcinogenesis has been documented in some human cancers (Fearon and Vogelstein 1990) and often involves the $p 53$ gene (Greenblatt et al. 1994). p53 mutations have been associated with genomic instability during tumor development in at least one clinical setting, esophageal cancer (Neshat et al. 1994), although in general human tissues are difficult to obtain at different stages of tumorigenesis in a single patient or in a genetically homogeneous population. For this reason, many laboratories are using mouse models to explore multistep models for carcinogenesis (Cardiff and Muller 1993; Kemp et al. 1993; Christofori and Hanahan 1994). Some of these models incorporate, as ours has done, a gene that is frequently mutated in the same type of cancer in human patients (Dietrich et al. 1993; Oltvai and Korsmeyer 1994). It is evident from recent work with such models that important physiological events-such as augmented angiogenic activity (Kandel et al. 1991; Shing et al. 1993; Fidler and Ellis 1994) or a diminished rate of apoptosis (Symonds et al. 1994)-can have major consequences during tumor progression. The Wnt-1 transgenic model has special advantages in this regard, because it is possible to examine mammary tissue at several stages of tumor development, ranging from early hyperplasia to metastatic growth (Tsukamoto et al. 1988). It will now be important to ask whether changes in angiogenic and apoptotic activity accompany the changes we have described here in histology, genomic composition, and integrity of specific genes.

\section{Materials and methods}

Mice

The Wnt-1 TG mice used in the crosses described here were the offspring of two Wnt-1 TG males from line 303 described previously (Tsukamoto et al. 1988). These mice were of mixed SJL $\times$ C57/BL/6 genetic background. The p53-deficient mice were from a pure $129 / \mathrm{Sv}$ line of mice containing one or two germ-line p53 null alleles (Harvey et al. 1993b). The two Wnt-1 males were crossed to heterozygous $(p 53+/-) 129 / \mathrm{Sv}$ females to derive $F_{1}$ mice of four possible genotypes $(p 53+/+$; Wnt-1 TG p53+/+; p53+/-; Wnt-1 TG p53+/-1. $\mathrm{F}_{1}$ p53+/- females were crossed to $F_{1}$ Wnt-1 TG $p 53+/-$ males to obtain $\mathrm{F}_{2}$ mice that carried any of the Wnt-1 TG p53 genotypes found in the $\mathrm{F}_{1}$ population as well as Wnt-1 TG p53-/- or $p 53-/-$. To obtain larger numbers of mice with $p 53-/-$ genotypes with or without the Wnt- 1 transgene, $\mathrm{F}_{2} p 53-1-$ females were mated to Wnt-1 TG p53 - / - males. All of the mice were monitored visually twice weekly for the appearance of tumors for up to 1 year. When a tumor of $\sim 0.5 \mathrm{~cm}$ in diameter was detected, the age of the mouse was recorded and used to generate the KaplanMeier plots in Figure 1. Once a tumor reached $1.5-2 \mathrm{~cm}$ in diameter, the tumor-bearing mouse was sacrificed, and tissue sections removed for histopathology. The remainder of the tumor was frozen at $-70^{\circ} \mathrm{C}$ for nucleic acid analyses.

\section{Nucleic acid isolation and analysis}

We determined the p53 and Wnt-1 genotypes of the offspring from the crosses by use of methods described previously (Tsukamoto et al. 1988; Donehower et al. 1992; Harvey et al. 1993a). To determine the coding sequence of the remaining $p 53$ allele in Wnt-1 TG p53 + / - mammary tumors that did not show LOH, total cellular RNA from a small tissue segment from each of four tumors was prepared using the RNAzol B kit (Tel-Test, Inc.) according to the manufacturer's instructions. We then used reverse transcriptase-PCR (with the RT-PCR kit from Perkin-Elmer Cetus) to amplify the p53 cDNA from the four tumor RNAs.

Initially, the amplification primers used were derived from exons 4 and 10 of the mouse cDNA, and these amplified exons $5-9$ of the murine $p 53$ gene. The nucleotide sequences of these primers were 5'-CAGTCTGGGACAGCCAAGTC-3' (exon 4) and 5'-CTCCCGGAACATCTGGAAGC-3' (exon 10). The amplified exon 4-10 fragments were purified from a low-temperature agarose gel following electrophoresis, treated with Klenow polymerase and T4 polynucleotide kinase, and then ligated into the plasmid cloning vector Bluescript II (Stratagene) at the SmaI site. Sequencing was performed on the Applied Biosystems automated sequencer with the SP6 and T7 universal sequencing primers adjacent to the insertion site. Standard dideoxy sequencing with the Sequenase sequencing kit (U.S. Biochemical) was also performed on parts of the cloned CDNA with two internal primers from exons 5 and 9: 5'-CGTGAGACGCTGCCCCCACCATG-3' (exon 5) and 5'-TTGCGGGGGAGAGGCGCTTGTGC-3' (exon 9).

Subsequently, fragments containing the remainder of the $p 53$ coding exons were also obtained by amplifying exons $2-4$ and exons $10-11$. The sequences of these primers used were $5^{\prime}-$ GGAATTCGCCATGGAGGAGTCACAGTCG-3' (exon 2); 5'GCAGAATAGCTTATTGAGGGGAGG-3' (exon 5); 5'-GCGCAAAGAGAGCGCTGCCC-3' (exon 8-9); 5'-CCCAAGCTTCAGTCTGAGTCAGGCCCCAC-3' (exon 11).

\section{Karyotype analysis}

Cytogenetic preparations were obtained essentially as described in Aldaz et al. (1992).

\section{Comparative genomic hybridization}

Comparative genomic hybridization was performed essentially as described in Kallioniemi et al. (1992). Briefly, tumor genomic DNA and normal genomic DNA were labeled with biotin 14 dATP (GIBCO-BRL) and digoxigenin-11-dUTP (Boehringer Mannheim) by nick translation or random priming. Double stranded labeled DNA with a fragment size distribution of 600 1000 bp gave optimal signals if labeled by nick translation. The size distribution was between 150 and $500 \mathrm{bp}$ when random primer labeling was used. Random priming was used in most of this work because it required less input DNA and more reliably produced good hybridization signals. Labeled tumor and normal 
genomic DNAs (60-100ng) and unlabeled mouse Cot-1 DNA (GIBCO-BRL) (10-20 $\mu \mathrm{g}$ ) were coprecipitated and dissolved in $10 \mu \mathrm{l}$ of hybridization solution to obtain a final composition of $50 \%$ formamide, $10 \%$ dextran sulfate, and $2 \times \operatorname{SSC}(\mathrm{pH} 7)$. This mixture was heated to $70^{\circ} \mathrm{C}$ for $5 \mathrm{~min}$ to denature the DNAs and incubated at $37^{\circ} \mathrm{C}$ for $5-30 \mathrm{~min}$. Normal mouse metaphase chromosomes prepared from fibroblast cultures were denatured at $80-85^{\circ} \mathrm{C}$ in $70 \%$ formamide, $2 \times \mathrm{SSC}$, for $5 \mathrm{~min}$ and dehydrated through an ethanol series. The hybridization mixture was applied to the slides, the coverslip sealed with rubber cement, and the slide incubated at $37^{\circ} \mathrm{C}$ for $4-5$ days. After hybridization, the slides were washed and stained with a single layer of avidin-FITC (Vector Laboratories) and anti-digoxigenin-rhodamine (Boehringer Mannheim). Slides were counterstained with $0.1-0.2 \mu \mathrm{M}$ DAPI in an antifade solution. The low DAPI concentration produced sufficient banding to permit identification of the mouse chromosomes.

Digital images of each of the fluorochromes in the specimens were obtained under computer control with a fluorescence microscope equipped with a CCD camera. Profiles of the fluorescence intensities of the normal and tumor DNA hybridization signals, and the intensity ratio profiles were calculated as described in Piper et al. (1995). The profiles were normalized so that the average value was 1.0 for the entire genome. Chromosomal regions where the ratio profile deviated significantly from the average were classified as either increases or decreases in DNA copy number.

\section{Histopathology of tumor tissue}

Histopathology of tumor tissues was as described previously (Medina 1973).

Southern blotting analysis of mammary tumors for gene amplification

DNA was isolated from tail and tumor tissue and $5 \mu \mathrm{g}$ was digested with BamHI as described previously (Donehower et al. 1992; Harvey et al. 1993a). The Southern blot was hybridized sequentially with several probes at the indicated temperatures: the 420-bp BamHI fragment of rat neu (Bargmann et al. 1986) at $55^{\circ} \mathrm{C}$, the $2.15-\mathrm{kb}$ HindIII fragment of mouse int-2/FGF3 (Mansour and Martin 1988$)$ at $65^{\circ} \mathrm{C}$, and the 600 -bp ClaI-HindIII fragment of human c-myc (Stone et al. 1987) at $55^{\circ} \mathrm{C}$. Following each hybridization, the blot was stripped of probe as recommended by the manufacturer. Quantitation was performed with a PhosphorImager (Molecular Dynamics).

\section{Northern blotting analysis of mammary tumors}

Portions of each tumor were used for RNA isolation by RNazol $B$ reagent (Tel-Test, Inc.) according to manufacturer's protocol. One microgram of poly $(-\mathrm{A})^{+} \mathrm{RNA}$ was electrophoresed through a $1 \%$ agarose formaldehyde gel and transfered to Hybond $\mathrm{N}$ (Amersham) in 20x SSC. Hybridizations were performed as described above. Additional probes and the corresponding hybridization temperatures used were the $1.7-\mathrm{kb}$ BamHI-EcoRI fragment of human PRAD-1/cyclin D1 (Arnold et al. 1989) at $55^{\circ} \mathrm{C}$ and the 1.6-kb HindIII fragment of mouse hst /FGF4 (Peters et al. 1989 ) at $65^{\circ} \mathrm{C}$. The blot was stripped following each hybridization, as recommended by the manufacturer and as confirmed by autoradiography.

\section{Acknowledgments}

We thank E. Aguilar-Cordova and J. Jones for helpful discussions. We are grateful to W. Fang, M. McArthur, F. Kittrell, T.
Doigg, A. Paladugu, and L. Yuschenkoff for excellent technical assistance, and R.F. Ramig for allowing us to use his mouse facility. We thank P. Hevezi, S. Sukumar, V. Pecenka, A. Arnold, G. Shackleford, and G. Lozano for gifts of plasmids. We also thank P. Wyde for help with the statistical assays. This work was supported by National Cancer Institute grants CA59967 (C.M.A.), CA54897 (L.A.D.), CA25215 (D.M.), CA45919 (D.P.), CA39832 (H.E.V.), a grant from the U.S. Army Breast Cancer Program (L.A.D.), and a grant from the Melanie Mann Bronfman Trust (H.E.V). L.A.D. is the recipient of a Research Career Development Award from the National Cancer Institute, and H.E.V. was an American Cancer Society research professor.

The publication costs of this article were defrayed in part by payment of page charges. This article must therefore be hereby marked "advertisement" in accordance with 18 USC section 1734 solely to indicate this fact.

\section{References}

Aldaz, C.M., A. Chen, L.S. Gollahon, J. Russo, and K. Zappler. 1992. Nonrandom abnormalities involving chromosome 1 and Harvey-ras-1 alleles in rat mammary tumor progression. Cancer Res. 52: 4791-4798.

Arnold, A., H.G. Kim, R.D. Gaz, R.L. Eddy, Y. Fukushima, M.G. Byers, T.B. Shows, and H.M. Kronenberg. 1989. Molecular cloning and chromosomal mapping of DNA rearranged with parathyroid hormone gene in a parathyroid adenoma. J. Clin. Invest. 83: 2034-2040.

Bargmann, C., M.-C. Hung, and R.A. Weinberg. 1986. Multiple independent activations of the neu oncogene by a point mutation altering the transmembrane domain of p185. Cell 45: 649-657.

Bischoff, F.Z., S.O. Yim, S. Pathak, G. Grant, M.J. Siciliano, B.C. Giovanella, L.C. Strong, and M.A. Tainsky. 1990. Spontaneous immortalization of normal fibroblasts from patients with Li-Fraumeni cancer syndrome: Aneuploidy and immortalization. Cancer Res. 50: 7979-7984.

Callahan, R. 1992. p53 mutations, another breast cancer prognostic factor. J. Natl. Cancer Inst. 84: 826-827.

Cardiff, R.D. and W.J. Muller. 1993. Transgenic models of mammary tumorigenesis. Cancer Surv. 16: 97-113.

Christofori, G. and D. Hanahan. 1994. Molecular dissection of multi-stage tumorigenesis in transgenic mice. Sem. Cancer Biol. 5: 3-12.

Clarke, A.R., C.A. Purdie, D.J. Harrison, R.G. Morris, C.C. Bird, M.L. Hooper, and A.H. Wyllie. 1993. Thymocyte apoptosis induced by p53-dependent and independent pathways. $\mathrm{Na}$ ture 352: 849-852.

Czosnek, H.H., B. Bienz, D. Givol, R. Zakut-Houri, D.D. Pravtcheva, F.H. Ruddle, and M. Oren. 1984. The gene and the pseudogene for mouse p53 cellular tumor antigen are located on different chromosomes. Mol. Cell. Biol. 4: 16381640.

Dameron, K.M., O.V. Volpert, M.A. Tainsky, and N. Bouck. 1994. Control of angiogenesis in fibroblasts by p53 regulation of thrombospondin-1. Science 265: 1582-1584.

Dietrich, W.F., E.S. Lander, J.S. Smith, A.R. Moser, K.A. Gould, C. Luongo, N. Borenstein, and W. Dove. 1993. Genetic identification of Mom-1, a major modifier locus affecting Mininduced intestinal neoplasia in the mouse. Cell 75: 631-639.

Donehower, L.A., M. Harvey, B.L. Slagle, M.J. McArthur, C.A. Montgomery, Jr., J.S. Butel, and A. Bradley. 1992. Mice deficient for p53 are developmentally normal but susceptible to spontaneous tumours. Nature 356: 215-221. 
Escot, C., C. Theillet, R. Lidereau, F. Spyratos, M.-H. Champeme, J. Gest, and R. Callahan. 1986. Genetic alteration of the c-myc protooncogene (MYC) in human primary breast carcinomas. Proc. Natl. Acad. Sci. 83: 4834-4838.

Farmer, G., J. Bargonetti, H. Zhu, P. Friedman, R. Prywes, and C. Prives. 1992. Wild type $\mathrm{p} 53$ activates transcription in vitro. Nature 358: 83-86.

Fearon, E.R. and B. Vogelstein. 1990. A genetic model for colorectal tumorigenesis. Cell 61: 759-767.

Fidler, I.J. and L.M. Ellis. 1994. The implications of angiogenesis for the biology and therapy of cancer metastasis. Cell 79: 185-188.

Greenblatt, M.S., W.P. Bennett, M. Hollstein, and C.C. Harris. 1994. Mutations in the p53 tumor suppressor gene: Clues to cancer etiology and molecular pathogenesis. Cancer Res. 54: 4855-4878.

Harvey, M., M.J. McArthur, C.A. Montgomery, Jr., J.S. Butel, A. Bradley, and L.A. Donehower. 1993a. Spontaneous and carcinogen-induced tumorigenesis in p53-deficient mice. $\mathrm{Na}$ ture Genet. 5: 225-229.

Harvey, M., M.J. McArthur, C.A. Montgomery, Jr., A. Bradley, and L.A. Donehower. 1993b. Genetic background alters the spectrum of tumors that develop in p53-deficient mice. FASEB I. 7: 938-943.

Harvey, M., A.T. Sands, R.S. Weiss, M.E. Hegi, R.W. Wiseman, P. Panayotis, B.C. Giovanella, M.A. Tainsky, A. Bradley, and L.A. Donehower. 1993c. In vitro growth characteristics of embryo fibroblasts isolated from p53-deficient mice. Oncogene 8: 2457-2467.

Jacks, T., L. Remington, B.O. Williams, E.M. Schmitt, S. Halachmi, R.T. Bronson, and R.A. Weinberg. 1994. Tumor spectrum analysis in p53-mutant mice. Curr. Biol. 4: 1-7.

Kallioniemi, A., O.-P. Kallioniemi, D. Sudar, D. Rutovitz, J.W. Gray, F. Waldman, and D. Pinkel. 1992. Comparative genomic hybridization for molecular cytogenetic analysis of solid tumors. Science 258: 818-821.

Kandel, J., E. Bossy-Wetzel, F. Radvanyi, M. Klagsbrun, J. Folkman, and D. Hanahan. 1991. Neovascularization is associated with a switch to the export of bFGF in the multistep development of fibrosarcoma. Cell 66: 1095-1104.

Kastan, M.B., O. Onyekwere, D. Sidransky, B. Vogelstein, and R.W. Craig. 1991. Participation of p53 protein in the cellular response to DNA damage. Cancer Res. 51: 6304-6311.

Kastan, M.B., Q. Zhan, W.S. El-Deiry, F. Carrier, T. Jacks, W.V. Walsh, B.S. Plunkett, B. Vogelstein, and A.J. Fornace, Jr. 1992. A mammalian cell cycle checkpoint pathway utilizing p53 and GADD45 is defective in ataxia-telangiectiasia. Cell 71: 587-597.

Kemp, C., L.A. Donehower, A. Bradley, and A. Balmain. 1993. Reduction of p53 gene dosage does not increase initiation or promotion but enhances malignant progression of chemically induced skin tumors. Cell 74: 813-822.

Kern, S.E., J.A. Pietenpol, S. Thiagalingam, A. Seymour, K.W. Kinzler, and B. Vogelstein. 1992. Oncogenic forms of p53 inhibit p53-regulated gene expression. Science 256: $827-$ 830.

Kwan, H., V. Pecenka, A. Tsukamoto, T.G. Parslow, R. Guzman, T.-P. Lin, W.J. Muller, F.S. Lee, P. Leder, and H.E. Varmus. 1992. Transgenes expressing the Wnt-1 and int-2 protooncogenes cooperate during mammary carcinogenesis in doubly transgenic mice. Mol. Cell. Biol. 12: 147-154.

Lammie, G.A., V. Fantl, R. Smith, E. Schuuring, S. Brookes, R. Michalides, C. Dickson, A. Arnold, and G. Peters. 1991. D11S287, a putative oncogene on chromosome $11 \mathrm{q} 13$, is amplified and expressed in squamous cell and mammary carcinomas and linked to BCL-1. Oncogene 6: 439-444.
Land, H., L. Parada, and R.A. Weinberg. 1983. Tumorigenic conversion of primary embryo fibroblasts requires at least two cooperating oncogenes. Nature 304: 596-602.

Lavigueur, A.L., V. Maltby, D. Mock, J. Rossant, T. Pawson, and A. Bernstein. 1989. High incidence of lung, bone, and lymphoid tumors in transgenic mice overexpressing mutant alleles of the p53 oncogene. Mol. Cell. Biol. 9: 3982-3991.

Lidereau, R., R. Callahan, C. Dickson, G. Peters, C. Escot, and I.U. Ali 1988. Amplification of the int-2 gene in primary human breast tumors. Oncogene Res. 2: 285-291.

Livingstone, L.R., A. White, J. Sprouse, E. Livanos, T. Jacks, and T. Tlsty. 1992. Altered cell cycle arrest and gene amplification potential accompany loss of wild-type p53. Cell 70: $923-935$.

Lowe, S.W., H.E. Ruley, T. Jacks, and D.E. Housman. 1993a. p53-dependent apoptosis modulates the cytotoxicity of anticancer agents. Cell 74: 957-967.

Lowe, S.W., E.M. Schmitt, S.W. Smith, B.A. Osborne, and T. Jacks. 1993b. p53 is required for radiation-induced apoptosis in mouse thymocytes. Nature 362: 847-849.

Lowe, S.W., S. Bodis, A. McClatchey, L. Remington, H.E. Ruley, D.E. Fisher, D.E. Housman, and T. Jacks. 1994. p53 status and the efficacy of cancer therapy in vivo. Science 266: 807810.

Lu, X. and D.P. Lane. 1993. Differential induction of transcriptionally active p53 following UV or ionizing radiation: Defects in chromosome instability syndromes? Cell 75: 765778.

Malkin, D., F.P. Li, L.C. Strong, J.F. Fraumeni, Jr., C.E. Nelson, D.H. Kim, J. Kassel, M.A. Gryka, F.Z. Bischoff, M.A. Tainsky, and S.H. Friend. 1990. Germ line p53 mutations in a familial syndrome of breast cancer, sarcomas, and other neoplasms. Science 250: 1233-1238.

Mansour, S.L. and G.R. Martin. 1988. Four classes of mRNA are expressed from the mouse int-2 gene, a member of the FGF gene family. EMBO I. 7: 2035-2041.

Medina, D. 1973. Preneoplastic lesions in mouse mammary tumorigenesis. Methods Cancer Res. 7: 3-53.

Medina, D., F. Shepherd, and T. Gropp. 1978. Enhancement of the tumorigenicity of preneoplastic mammary lines by enzymatic dissociation. J. Natl. Cancer Inst. 60: 1121-1126.

Neshat, K., C.A. Sanchez, P.C. Galipeau, P.L. Blount, D.S. Levine, G. Joslyn, and B. Reid. 1994. p53 mutations in Barrett's adenocarcinoma and high-grade dysplasia. Gastroenterology 106: 1589-1595.

Oltvai, Z.N. and S.J. Korsmeyer. 1994. Checkpoints of dueling dimers foil death wishes. Cell 79: 189-192.

Peters, G., A.E. Lee, and C. Dickson. 1986. Concerted activation of two potential proto-oncogenes in carcinomas induced by mouse mammary tumour virus. Nature 320: 628-631.

Peters, G., S. Brookes, R. Smith, M. Placzek, and C. Dickson. 1989. The mouse homolog of the hst/k-FGF gene is adjacent to int -2 and is activated by proviral insertion in some virally induced mammary tumors. Proc. Natl. Acad. Sci. 86: 56785682.

Piper, J., D. Rutovitz, D. Sudar, A. Kallioniemi, O.-P. Kallioniemi, F.W. Waldman, J.W. Gray, and D. Pinkel. 1995. Computer image analysis of comparative genomic hybridization. Cytometry 19: 10-26.

Purdie, C.A., D.J. Harrison, A. Peter, L. Dobbie, S. White, S.E.M. Howie, D.M. Salter, C.C. Bird, A.H. Wyllie, M.L. Hooper, and A.R. Clarke. 1994. Tumour incidence, spectrum and ploidy in mice with a large deletion in the p53 gene. Oncogene 9: 603-609.

Rotter, V., D. Wolf, D. Pravtcheva, and F.H. Ruddle. 1984. Chromosomal assignment of the murine gene encoding the trans- 
formation-related protein p53. Mol. Cell. Biol. 4: 383-385.

Sass, B. and T.B. Dunn. 1979. Classification of mouse mammary tumors in Dunn's miscellaneous group, including recently reported types. J. Natl. Cancer Inst. 62: 1287-1293.

Shackleford, G.M., C.A. McArthur, H.C. Kwan, and H.E. Varmus. 1993. Mouse mammary tumor virus infection accelerates mammary carcinogenesis in Wnt-1 transgenic mice by insertional activation of int-2/Fgf-3 and hst/Fgf-4. Proc. Natl. Acad. Sci. 90: 740-744.

Shing, Y., G. Christofori, D. Hanahan, Y. Ono, R. Sasada, K. Igarashi, and J. Folkman. 1993. Betacellulin: A mitogen from pancreatic beta cell tumors. Science 259: 1604-1607.

Slamon, D.J., G.M. Clark, S.G. Wong, W.J. Levin, A. Ullrich, and W.L. McGuire. 1987. Human breast cancer: Correlation of relapse and survival with amplification of the HER-2/neu oncogene. Science 235: 177-182.

Srivastava, S., Z. Zou, K. Pirollo, W. Blattner, and E.H. Chang. 1990. Germ-line transmission of a mutated p53 gene in a cancer prone family with Li-Fraumeni syndrome. Nature 348: 747-749.

Stone, J., T. de Lange, G. Ramsay, E. Jakobovits, J.M. Bishop, H. Varmus, and W. Lee. 1987. Definition of regions in human c-myc that are involved in transformation and nuclear localization. Mol. Cell. Biol. 7: 1697-1709.

Symonds, H., L. Krall, L. Remington, M. Saenz-Robles, S. Lowe, T. Jacks, and T. Van Dyke. 1994. p53-dependent apoptosis suppresses tumor growth and progression in vivo. Cell 78: 703-711.

Thor, A.D., D.H. Moore, S.M. Edgerton, E.S. Kawasaki, E. Reihsaus, H.T. Lynch, J.N. Marcus, L. Schwartz, L.-C. Chen, B.H. Mayall, and H.S. Smith. 1992. Accumulation of p53 tumor suppressor gene protein: An independent marker of prognosis in breast cancers. 1. Natl. Cancer Inst. 84: 845-855.

Tsukamoto, A.S., R. Grosschedl, R.C. Guman, T. Parslow, and H.E. Varmus. 1988. Expression of the int-1 gene in transgenic mice is associated with mammary gland hyperplasia and adenocarcinomas in male and female mice. Cell 55: 619-625.

Yin, H., M.A. Tainsky, F.Z. Bischoff, L.C. Strong, and G.M. Wahl. 1992. Wild-type p53 restores cell cycle control and inhibits gene amplification in cells with mutant p53 alleles. Cell 70: 937-948.

Yonish-Rouach, E., D. Resnitzky, J. Lotem, L. Sachs, A. Kimchi, and M. Oren. 1991. Wild-type p53 induces apoptosis of myeloid leukemic cells that is inhibited by interleukin-6. $\mathrm{Na}$ ture 352: 345-347. 


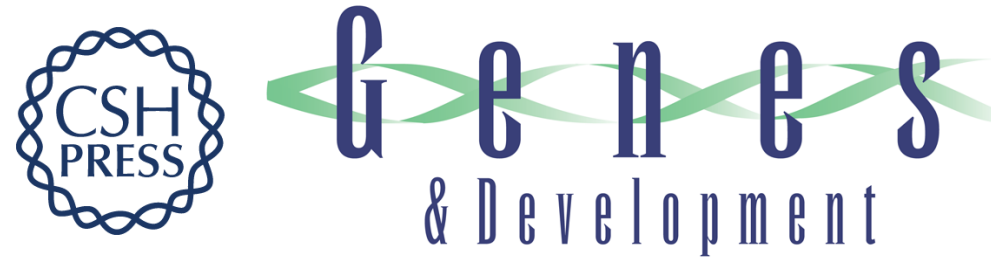

\section{Deficiency of p53 accelerates mammary tumorigenesis in Wnt-1 transgenic mice and promotes chromosomal instability.}

L A Donehower, L A Godley, C M Aldaz, et al.

Genes Dev. 1995, 9:

Access the most recent version at doi:10.1101/gad.9.7.882

References This article cites 59 articles, 19 of which can be accessed free at:

http://genesdev.cshlp.org/content/9/7/882.full.html\#ref-list-1

License

Email Alerting

Service

Receive free email alerts when new articles cite this article - sign up in the box at the top right corner of the article or click here.

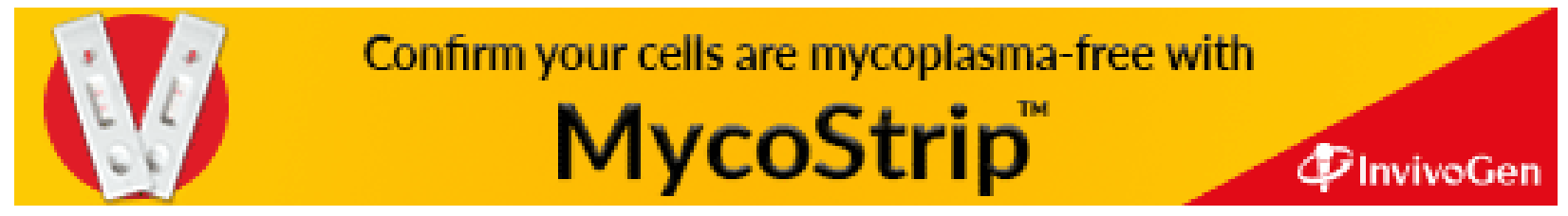

